\title{
Long-Term Memory for Spatial Locations in a Food-Storing Bird (Poecile atricapilla) Requires Activation of NMDA Receptors in the Hippocampal Formation During Learning
}

\author{
Michael W. Shiflett, Michelle L. Tomaszycki, Alexander Z. Rankin, and Timothy J. DeVoogd \\ Cornell University
}

\begin{abstract}
Food-storing birds use a form of long-term memory to recover their hidden food caches that depends on the hippocampal formation (HF). The authors assessed whether food-storing birds' long-term memory for spatial locations requires $N$-methyl-D-aspartate receptor (NMDA-R)-dependent synaptic plasticity. Black-capped chickadees (Poecile atricapilla) were given bilateral infusions of the NMDA-R antagonist AP5 into the hippocampus, and their memory on a spatial reference memory task was assessed. NMDA-R inactivation during learning prevented formation of long-term spatial memories but did not affect short-term memory and retrieval processes. NMDA-R inactivation immediately following learning did not disrupt long-term memory formation. NMDA-R inactivation disrupted the learning of multiple serially encoded reward locations when a 180-min delay separated successive learning episodes, suggesting that NMDA-R activity has a role in the incorporation of new information into existing long-term memory, as well as in forming unitary long-term memories.
\end{abstract}

Food-storing bird species create scattered food caches in their environment and rely on an accurate and extensive memory for spatial locations to recover their caches. Such memory demands are associated with adaptations in both the brain and behavior of food-storing bird species (reviewed by Smulders \& DeVoogd, 2000). Across species, greater food-storing intensity has been associated both with a relative increase in the size of memoryrelated brain regions, such as the hippocampal formation $(\mathrm{HF})$ and septum (Basil, Kamil, Balda, \& Fite, 1996; Hampton, Sherry, Shettleworth, Khurgel, \& Ivy, 1995; Healy \& Krebs, 1992, 1996; Krebs et al., 1996; Sherry, Vaccarino, Buckenham, \& Herz, 1989; Shiflett, Gould-Beierle, Smulders, \& DeVoogd, 2002), and with superior performance on spatial memory tasks (Balda, Kamil, Bednekoff, \& Hile, 1997; Bednekoff, Balda, Kamil, \& Hile, 1997; Biegler, McGregor, Krebs, \& Healy, 2001; Clayton \& Krebs, 1994; Kamil, Balda, \& Olson, 1994; Olson, Kamil, Balda, \& Nims, 1995). Similarly, within one such species (black-capped chickadees, Poecile atricapilla), variation in food-storing intensity is positively related to relative HF size and memory ability (Pravosudov \& Clayton, 2002; Smulders, Sasson, \& DeVoogd, 1995; Smulders, Shiflett, Sperling, \& DeVoogd, 2000).

Although these findings clearly indicate that a larger $\mathrm{HF}$ is important for remembering the locations of hidden food caches, this fact does not itself address the neural mechanisms underlying

Michael W. Shiflett, Michelle L. Tomaszycki, Alexander Z. Rankin, and Timothy J. DeVoogd, Department of Psychology, Cornell University.

This research was supported by National Institutes of Health Grants MH56093 to Timothy J. DeVoogd and MH12934 to Michael W. Shiflett. We thank Kevin Bath for composing Figures 2 and 5.

Correspondence concerning this article should be addressed to Michael W. Shiflett, who is now at the Department of Neuroscience, University of Pittsburgh, 446 Crawford Hall, Pittsburgh, PA 15260. E-mail: shiflett@ bns.pitt.edu the specialization in memory (Bolhuis \& Macphail, 2001; Macphail \& Bolhuis, 2001). Manipulations of the structure and physiology of the avian HF have highlighted certain features of memory that are dependent on HF function. Lesions of the avian $\mathrm{HF}$ disrupt tasks that require memory for spatial information, including memory for hidden food caches (Bingman \& Yates, 1992; Colombo, Swain, Harper, \& Alsop, 1997; Hampton \& Shettleworth, 1996a, 1996b; Sherry \& Vaccarino, 1989). However, the avian HF appears to participate only in the initial acquisition and short-term maintenance of memory. Thus, temporary neural inactivation of the HF of black-capped chickadees prevents the acquisition of memory. However, such treatment at the time of memory retrieval has no disruptive effect if retrieval occurs at least $3 \mathrm{hr}$ after memory acquisition (Shiflett, Smulders, Benedict, \& DeVoogd, 2003).

The above results suggest that the avian and mammalian HF have a common function in the formation of long-term spatial memory. The formation of certain types of long-term memory in mammals depends on synaptic plasticity initiated by activity of the $N$-methyl-D-aspartate receptor (NMDA-R) in the hippocampus Genetic and pharmacological manipulation of NMDA-R activity in the mammalian hippocampus prevents long-term memory for spatial locations, as tested in both the Morris water maze (Morris, Anderson, Lynch, \& Baudry, 1986; Steele \& Morris, 1999; Tsien, Huerta, \& Tonegawa, 1996) and radial arm maze (Bolhuis \& Reid, 1992; Caramanos \& Shapiro, 1994; Shapiro \& Caramanos, 1990). However, the requirement for NMDA-R activation depends on the animal's familiarity with the testing environment. NMDA-R activation is required to form long-term memory when new learning occurs in a familiar environment. However, new learning in a novel environment does not require NMDA-R activity (Bannerman, Good, Butcher, Ramsay, \& Morris, 1995; Moser \& Moser, 2000; Saucier \& Cain, 1995; Steele \& Morris, 1999). This suggests that the prior experience of the animal may determine the extent to which NMDA-R activity is necessary for long-term memory for- 
mation. Furthermore, the role of NMDA receptors may not be confined to memory acquisition. Prevention of NMDA-R activity following memory acquisition inhibits long-term memory formation (Shimizu, Tang, Rampon, \& Tsien, 2000). These findings illustrate the important and complex role of NMDA-R activity with respect to long-term memory formation in the mammalian hippocampus.

In the experiments presented here, we examine whether NMDA-R activity within the HF of food-storing birds has a role in the formation of long-term spatial memory. Such information is important in establishing whether birds and mammals use similar mechanisms to form long-term memories. To determine the function of NMDA-R activity on long-term memory formation, we infused the NMDA antagonist D-2 amino 5-phosphonopentanoic acid (AP5), bilaterally into the hippocampus at different times during a spatial reference memory task. In Experiment 1, we examine whether NMDA-R activity has a role in memory formation or memory retrieval, by preventing NMDA-R activity prior to either the acquisition or the retrieval of a new memory. In Experiment 2, we determine whether postacquisition NMDA-R activity is necessary for long-term memory formation, by preventing NMDA-R activity immediately following a learning episode. In Experiment 3, we examine how NMDA-R activity influences the sequential encoding of multiple reward locations.

\section{General Method}

\section{Subjects}

Eleven black-capped chickadees (Poecile atricapilla) were caught near Ithaca, NY under state and federal permits. Five birds were caught between
September and October 2001 and were used in Experiment 1. An additional 6 birds were caught between July and September 2002 and were used in Experiments 2 and 3. Experiments were performed from September through December, 2001, and August through November, 2002. Thus testing covered the interval during which high levels of caching occur in the wild. Birds were fed daily on a diet of mealworms and a mix consisting of ground beef, carrot baby food, hardboiled eggs, wheat germ, and turkey pellets. Water was provided ad libitum. Birds were housed in wire cages (61 cm long $\times 41 \mathrm{~cm}$ high $\times 41 \mathrm{~cm}$ wide) and kept on a 10:14-hr light-dark cycle.

\section{Testing Apparatus}

Memory tests took place in a $4.5 \mathrm{~m}$ long $\times 4.0 \mathrm{~m}$ wide $\times 2.5 \mathrm{~m}$ high testing room (see Figure 1). A number of wooden feeders were arranged on the walls of the testing room. Each feeder consisted of a wooden block painted dark green, containing a 9-mm-deep hole and a 10-cm dowel protruding from the base. Depending on the experiment, one or two of the feeders was baited with one half of a mealworm placed inside the hole. All feeders were fitted with a string attached to the dowel, the end of which was knotted and covered the feeder holes. This prevented birds from casually observing whether or not a feeder was baited. Birds entered the room from their home cages through a trapdoor in the wall. Prior to the testing phase, we pretrained birds to enter the test room when the trap door was raised, to search for mealworms by pulling knots from feeders, and to leave the test room and return to the home cage when the test room lights were turned off. We observed the birds' behavior through a window of darkened Plexiglas.

\section{Surgery}

One to 3 days following pretraining, we anesthetized $(5 \mathrm{mg} / \mathrm{kg} \mathrm{im}$ xylazine and $87.5 \mathrm{mg} / \mathrm{kg}$ im ketamine) the birds and affixed bilateral

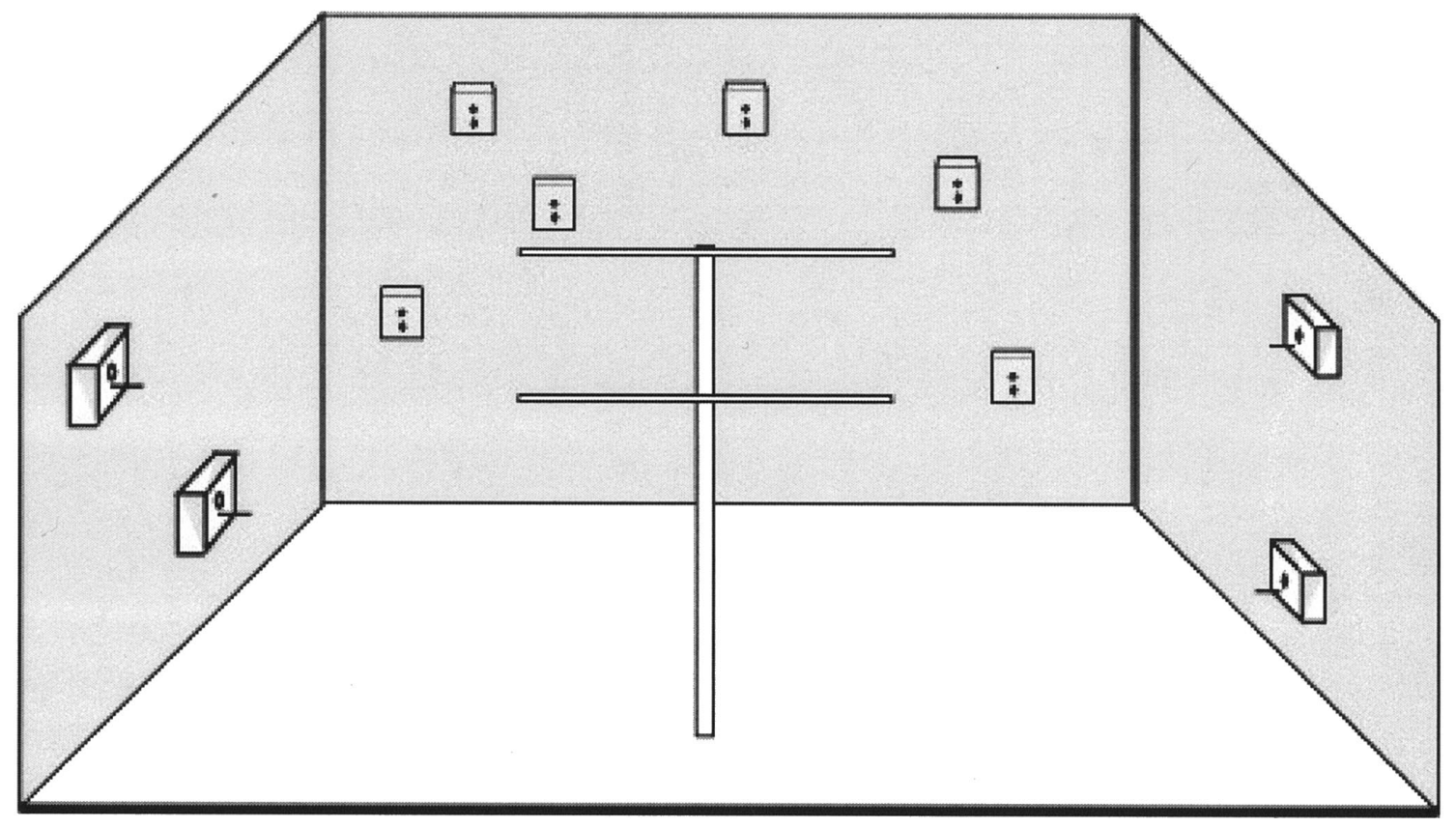

Figure 1. Schematic of the testing room and feeder. The testing room was $4.5 \mathrm{~m} \times 4.0 \mathrm{~m} \times 2.5 \mathrm{~m}$. Three of the walls were covered with hardware cloth stretching from the ceiling to $1 \mathrm{~m}$ above the floor. Ten feeders were hung on the hardware cloth walls in a pseudorandom arrangement. Each feeder consisted of a $9.0 \mathrm{~cm} \times 11.5 \mathrm{~cm}$ $\times 4.0-\mathrm{cm}$ block containing a 9-mm-deep hole. A wooden dowel was inserted into the wooden block three centimeters below the hole. Centered in the room was a wooden perch $1.5 \mathrm{~m}$ in height. All feeders were painted green and appeared identical. 
cannulas (26 gauge, $4 \mathrm{~mm}$ long) to their skulls with cyanoacrylate glue and dental cement, using standard stereotaxic techniques. We positioned cannulas in the dorsal-ventral plane such that the ventral tip of each cannula contacted the dorsal surface of the HF, and in the anterior-posterior plane $2.2 \mathrm{~mm}$ rostral to the site in the brain where the midline meets the cerebellum. Each cannula was positioned laterally $1 \mathrm{~mm}$ from the midline in the medial-lateral plane. Birds were allowed 2 days to recover.

\section{Intrahippocampal Administration of NMDA Antagonist}

We infused the NMDA antagonist AP5 (30 mM, $0.6 \mu$ l per side; Sigma, St. Louis, MO) or vehicle $(0.8 \%$ [wt/vol] saline, $0.6 \mu \mathrm{l}$ per side) into the HF. During infusion, we restrained birds by hand, and inserted a 32 -gauge needle attached to a 2.5- $\mu$ l Hamilton syringe into each cannula. We delivered infusates gradually over the course of $1 \mathrm{~min}$. We left the needle in the cannula for an additional minute to allow for fluid dispersal.

\section{Verification of Infusion Sites}

We anesthetized birds with an overdose of Chloropent and perfused them transcardially with $0.8 \%$ saline, followed by $10 \%$ (wt/vol) Formalin$0.8 \%$ saline. We removed the brains from the skulls, and transferred them to $30 \%$ (wt/vol) sucrose/10\% Formalin for $48 \mathrm{hr}$. We then embedded brains in $10 \%$ gelatin/30\% sucrose and cut them at $40 \mu \mathrm{m}$ on a freezing microtome. We mounted sections on slides, stained the sections with Cresyl violet, and examined them with a light microscope.

\section{Experiment 1: NMDA-R Inactivation During Memory Acquisition and Retrieval}

In this experiment, we examined the effects of NMDA-R inactivation during the acquisition and retrieval of memories of spatial locations. We used a spatial reference memory task, in which birds associate a particular location with a reward. To assess the effects of NMDA-R inactivation on memory, we delivered infusates prior to the acquisition of a new memory, or prior to the retrieval of a previously formed memory. All birds experienced each of the experimental conditions, and the order of conditions was block randomized across birds. The arrangement of feeders on the walls of the testing room was kept the same for all conditions. It has been shown that NMDA-R blockade is more likely to produce a memory deficit if the animal is forced to reuse the same set of cues to form novel associations (Steele \& Morris, 1999). The rewarded feeder was randomly selected from the 10 feeders for each condition.

\section{Method}

Reference memory task. Birds learned that 1 feeder within an array of 10 possible feeders in the testing room contained a reward. Upon first entering the testing arena, birds randomly searched for the reward among the 10 possible locations. When the birds found the baited feeder, they were allowed to consume the mealworm, then the lights in the testing room were turned off and the birds returned to their cages. We rebaited the feeder that previously contained the mealworm and replaced any knots the birds had removed from this and other feeders while they searched for the bait. Two minutes after the birds returned to their home cage, we again released birds into the testing room, and again they searched for the bait.

Birds repeated this training process until they had successfully attained our criterion for learning, which we defined as making one or fewer errors on two of three consecutive entries into the testing room (chance performance would be 4.5 errors per entry). Errors were counted whenever a bird removed a knot from a feeder that did not contain a reward. We counted only initial visits to feeders. We did not count as errors revisits to feeders whose knots had already been removed because it was not possible to determine whether the bird was rechecking a feeder or merely perching at the feeder. All birds achieved this performance criterion within $15 \mathrm{~min}$ of training. This insured that training occurred while the AP5 was most likely interfering with NMDA-R activity. Birds were food deprived 2-3 hr prior to testing, and testing took place daily from 9 a.m. to 2 p.m.

After birds had learned according to our criterion, a delay of either 15 min or 180 min ensued, during which the birds remained in their cages. Following the delay, we released birds into the testing room for a single probe trial, in which we baited the same feeder as during the previous entries. We recorded the number of errors the bird made during the probe trial. We administered an additional probe trial in the same manner on the following day. After this second probe trial, we trained birds to remember a new reward location but did not administer any infusions. We interspersed these noninfusion training trials between experimental training and treatments so as to reduce any order effects from the various treatments.

Effects of infusion on the acquisition and retrieval of spatial memory. In a particular test series, birds received intrahippocampal infusions either 15 min prior to training or $15 \mathrm{~min}$ prior to the probe trial. Infusions prior to training assessed the effect of the infusate on the acquisition and initial consolidation of memory. Infusions prior to the probe trial assessed the effect of infusate on the retrieval of memory (see Figure 2). An additional probe trial was administered on the following day. Each bird was used in all phases of the experiment (treatment order was randomized across individual birds).

A

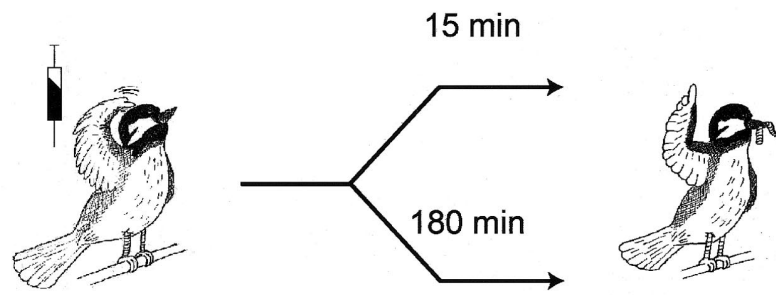

Learning episode

Retrieval Test

B

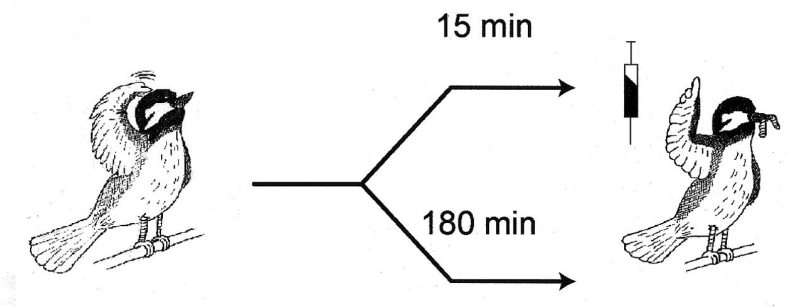

Learning episode

Retrieval Test

Figure 2. Design of Experiment 1. A: Birds encode the location of a single food reward hidden among 10 possible locations. Prior to the learning episode, birds were administered intrahippocampal infusions of either D-2 amino 5-phosphonopentanoic acid (AP5) or saline. Birds' memory was probed with a retrieval test $15 \mathrm{~min}$ or $180 \mathrm{~min}$ after the learning episode. A second retrieval test (not shown) was administered $24 \mathrm{hr}$ after the first learning episode. B: Chickadees learn the location of a hidden food reward. Birds' memory was probed with a retrieval test $15 \mathrm{~min}, 180 \mathrm{~min}$, or $24 \mathrm{hr}$ after the learning episode. Intrahippocampal infusions of either AP5 or vehicle were administered prior to each retrieval test. 


\section{Results}

Numbers of trials to reach criterion. Our criterion for learning required the birds to make one or fewer errors per entry in two of three consecutive entries into the arena. Therefore, the fewest entries a bird could make to demonstrate learning was two. A paired $t$ test revealed no significant difference between bird's acquisition scores in the trials in which they were receiving AP5 15 min prior to training compared with the trials in which they were receiving saline (mean $[ \pm S E M]$ number of entries: AP5 = $4.58 \pm 0.50$, saline $=5.42 \pm 0.65), t(5)=0.94$. To perform successfully in this phase of the memory task, birds had to acquire a new spatial memory, store it in short-term memory, and retrieve that memory. Administration of AP5 to the HF just before training had no significant effect on any of these processes.

Performance on probe trials. After birds learned the location of the baited feeder, a delay of either $15 \mathrm{~min}$ or $180 \mathrm{~min}$ ensued. Following the delay, we tested birds on a single probe trial for retrieval of their previously formed spatial memory. Performance on the probe trial was analyzed using a $2 \times 2 \times 2$ repeatedmeasures General Linear Model analysis of variance (ANOVA), with the three variables representing the effects of the infusate (AP5 or saline), the time of infusion (before the acquisition phase or before the probe trial), and the delay duration before the probe trial (15 or $180 \mathrm{~min}$ ). The dependent measure was the number of errors the birds made during the probe trials. There was no main effect of infusate, $F(1,4)=1.25$, or time of infusion, $F(1,4)=$ 1.81 , on the number of errors the birds made (infusion before learning, see Figure 3A; infusion before retrieval, see Figure 3B). However, there was a significant main effect of delay duration, $F(1,4)=17.05 p<.01$. There were no significant second-order interactions: Infusate $\times$ Delay, $F(1,4)=7.53$; Infusate $\times$ Time, $F(1,4)=2.23$; Delay $\times$ Time, $F(1,4)=2.76$. There was a significant third-order interaction: Infusate $\times$ Delay $\times$ Time, $F(1$, $5)=8.45, p<.05$. Thus AP5 impaired memory, but only when we administered it before acquisition and tested memory $180 \mathrm{~min}$ later: paired $t$ test, $t(4)=2.67, p=.05$ (Figure 3).

A separate analysis was undertaken for the 24-hr probe trial, because these data were not independent of the other probe trial data. Performance on the probe trial was analyzed with $2 \times 2$ repeated-measures GLM ANOVA, with the two variables representing the drug (AP5 or saline) and the time of infusion (before acquisition or before the probe trial). There was no main effect of drug, $F(1,4)=4.36$. There was a main effect of time of infusion, $F(1,4)=18.69, p=.01$, and there was no significant interaction, $F(1,4)=5.21$. A paired $t$ test revealed significantly more errors at $24 \mathrm{hr}$ retention in birds that received infusions of AP5 prior to memory acquisition, than in birds that had received saline (AP5: $M=4.70 \pm 0.86$, saline: $M=1.9 \pm 0.4)$ : paired $t$ test, $t(4)=2.67$ $p=.05$ (Figure 3A).

These results indicate that AP5 administration prior to learning prevents the formation of long-term memory, as shown by the poor recall of memory $180 \mathrm{~min}$ following the original learning episode. AP5 infusion does not disrupt short-term learning, however, as birds that received AP5 accurately recalled information $15 \mathrm{~min}$ following the original learning episode. Furthermore, AP5 infusion does not disrupt retrieval processes themselves, as birds that received AP5 prior to memory retrieval showed no impairment.
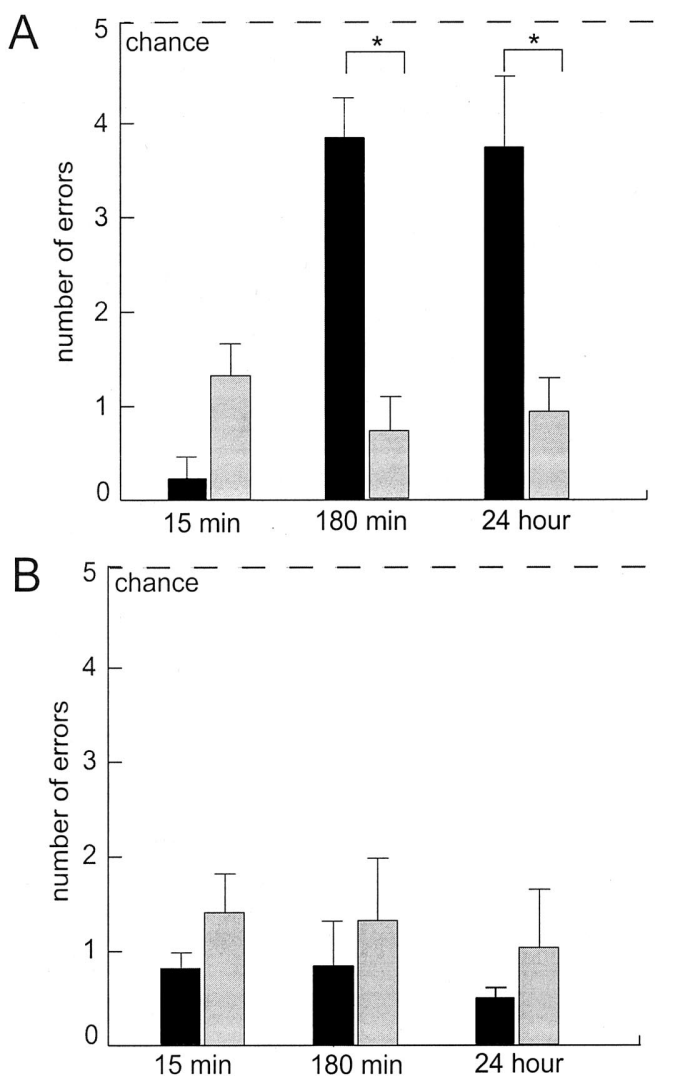

Figure 3. Results of Experiment 1. A: Birds received infusions of D-2 amino 5-phosphonopentanoic acid (AP5; black bars) or saline (gray bars) prior to encoding the hidden reward location. The average ( $\pm S E$ ) number of errors is plotted for the different retrieval tests, which occurred either 15 min, $180 \mathrm{~min}$, or $24 \mathrm{hr}$ after the learning episode. When birds received AP5 prior to acquiring a memory, they made significantly more errors at the 180-min and 24-hr retrieval tests than when they received saline prior to acquiring a memory. Asterisks indicate a significant difference between AP5 and saline $(p<.05)$. B: Birds received infusions of AP5 (black bars) or saline (gray bars) prior to memory retrieval tests that occurred $15 \mathrm{~min}, 180 \mathrm{~min}$, or $24 \mathrm{hr}$ after the learning episode. Birds did not differ in the number of feeders checked, whether they received infusions of AP5 or saline prior to memory retrieval. The hatched lines indicate chance number of errors before finding 1 of 10 possible locations.

\section{Experiment 2: NMDA-R Inactivation Following Memory Acquisition}

The results from Experiment 1 demonstrate that NMDA-R activation is necessary for the formation of long-term memory. It is less clear whether our infusion treatment affected processes that occur during memory acquisition, or processes that occur during a postacquisition consolidation period. Some results suggest that NMDA-R activation is necessary during both phases for the formation of long-term memories (Shimizu et al., 2000). We tested this hypothesis by blocking NMDA-R activity immediately following a learning episode, and then examining memory for the learned location on subsequent probe trials. 


\section{Method}

Reference memory task. The birds performed a memory task that was identical to that used in Experiment 1, except in the following ways. Two locations were rewarded instead of a single location, and the number of potential locations was increased from 10 to 19. Because of the increased number of feeders, the criterion for learning was changed, such that birds had to make four or fewer errors before finding the two feeders on two of three consecutive entries into the arena to demonstrate learning. As in Experiment 1, birds were given $15 \mathrm{~min}$ to demonstrate initial acquisition of learning and all acquired the task within this time.

Effects of infusion on memory for spatial locations. To test the effects of infusate on the postacquisition consolidation process, we administered infusions immediately following the training episode. A probe trial was administered $24 \mathrm{hr}$ after the training episode. Birds participated in all conditions, and the treatments were counterbalanced across birds to reduce order effects.

\section{Results}

We compared the total number of feeders birds checked (including the baited feeders) across the two drug conditions. A paired $t$ test revealed no significant difference in the number of errors birds made when the birds experienced the two conditions (AP5: $M=3.30 \pm 0.84$, saline: $M=3.50 \pm 0.56), t(5)=-0.21$ (see Figure 4). Both groups were significantly better than chance (11.6 errors) at $24 \mathrm{hr}$ : AP5 versus chance, $t(5)=7.90, p<.01$; saline versus chance, $t(5)=11.50, p<.01$. These results demonstrate that AP5 infusion immediately following the acquisition of new information does not prevent the consolidation of this information into long-term memory, as assessed $24 \mathrm{hr}$ after learning.

\section{Experiment 3: NMDA-R Inactivation and Memory for Multiple Reward Locations}

Our results suggest that long-term memory for rewarded locations is dependent on NMDA-R activity during the acquisition or

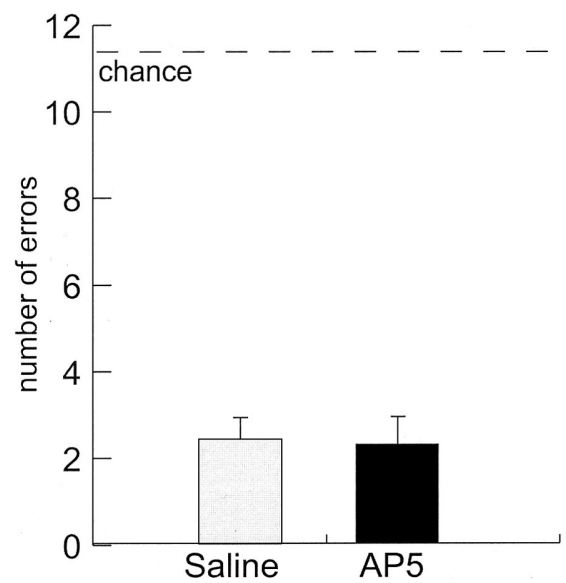

Figure 4. Results of Experiment 2. Birds received intrahippocampal infusions of D-2 amino 5-phosphonopentanoic acid (AP5) or vehicle immediately following a learning episode. Birds' memory was then probed $24 \mathrm{hr}$ after the learning episode. The hatched line indicates chance performance for finding two hidden rewards among 19 possible locations. Birds did not differ in the number of errors on the retrieval test, whether they received AP5 or saline immediately following the learning episode. learning episode. In Experiment 3, we examined how NMDA-R activity influences the encoding of multiple reward locations. The serial encoding of multiple items in memory is especially relevant to the study of food-storing species because it more closely resembles their natural food-storing behavior. In this experiment, birds first learned that a single location contained a food reward. Either $15 \mathrm{~min}$ or $180 \mathrm{~min}$ after the first learning episode, birds learned that, in addition to the first location, a second location contained a food reward. Immediately prior to this second learning episode, we interrupted NMDA-R activity by performing intrahippocampal infusions of AP5. The following day, we administered a single probe trial to determine memory retention for both reward locations.

A second aim of this experiment was to determine whether rearranging the feeders for each trial would prevent memories from being disrupted by NMDA-R blockade. For each drug or delay condition, a novel arrangement of feeders was used. If NMDA-Rs are especially important in birds for forming new spatial associations in a familiar context (as they are in mammals), then we would expect no deficits resulting from AP5 infusion when we rearranged feeders for each condition. A memory deficit might still be found for the second reward location when there is a long delay between learning the first and second reward locations if a long delay provides enough time for the novel context to become familiar.

\section{Method}

Memory task. The task we used was a reference memory task conducted in a manner similar to that of Experiments 1 and 2. In this task, birds first found a single reward in 1 of 19 possible locations. After birds reached our criterion performance (two errors on two of three consecutive entries into the arena), they learned that, in addition to the previously rewarded location, a second location contained a reward. Birds learned about the second rewarded location either $15 \mathrm{~min}$ or $180 \mathrm{~min}$ after the first learning episode took place. To facilitate learning about the second reward location, we removed the knots from all feeders and placed a visible mealworm in both reward locations. The trial continued until the bird found and ate both worms. Following this trial, both reward locations were rebaited and all knots were replaced over the bait. We trained birds on both locations until they reached a criterion of four or fewer errors before finding the two worms on two of three consecutive entries into the arena. We administered a probe trial $24 \mathrm{hr}$ after completion of the second training episode and recorded the number of errors the birds made while retrieving rewards from both locations.

All errors before initially finding a baited feeder were assigned to that feeder (regardless of whether it had been learned first), and all subsequent errors to the remaining feeder. Because there was no constraint on which location the bird recovered first, this error-counting method should not be biased toward one location over another.

Arrangement of feeders. In contrast to Experiments 1 and 2, the arrangement of feeders was varied from trial to trial. This provided the birds with a unique arrangement of feeders for each trial. The rewarded feeders were pseudorandomly selected such that at least two unbaited feeders were interposed between the two reward feeders.

Effects of NMDA-R inactivation on memory for multiple locations. We infused birds with AP5 or vehicle 15 min prior to their learning the second reward location (see Figure 5). All birds participated in all conditions, and the order of infusates and delay intervals were counterbalanced across birds. The location of the 19 feeders was changed for each experimental condition. 


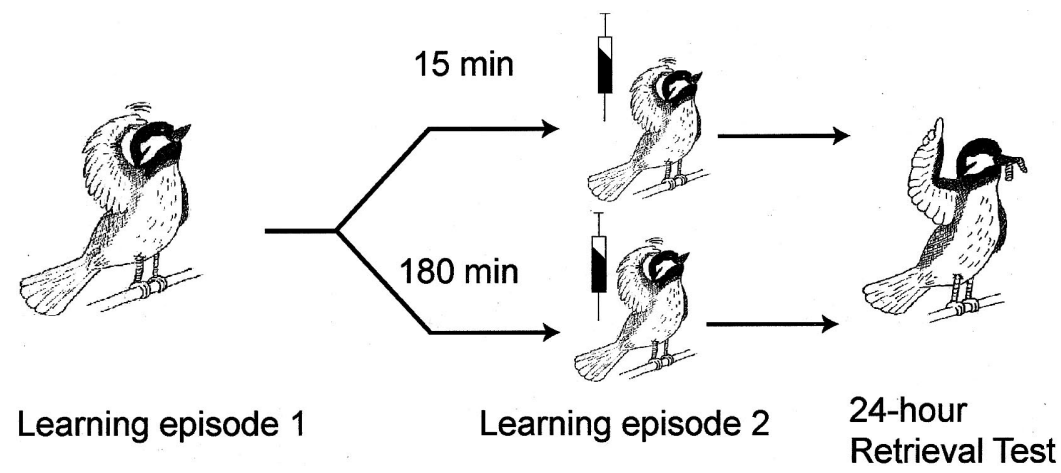

Figure 5. Design of Experiment 3: In Episode 1, birds learned the location of one reward item hidden among 19 possible locations. In Episode 2, birds learned that, in addition to the first reward item, a second reward item was hidden in another location. This second learning episode occurred either 15 or $180 \mathrm{~min}$ after the first learning episode. Birds received intrahippocampal infusions of AP5 or saline prior to the second learning episode. Birds' memory was then probed with a retrieval test $24 \mathrm{hr}$ after Episode 1.

\section{Results}

Performance on the 24-hour probe trial was analyzed using a doubly multivariate repeated measures model. The independent variables were the drug used during infusion (AP5 or saline), and the delay between learning episodes (15 $\mathrm{min}$ or $180 \mathrm{~min}$ ). The dependent variables were the number of errors the birds made in locating the first and second reward locations during the probe trial.

Memory for the first reward location. As shown in Figure 6, there was no significant effect of drug, $F(1,5)=3.28$, or of delay, $F(1,5)=3.16$. There was no significant interaction between drug and delay, $F(1,5)=0.05$. The infusion treatments the birds experienced following their learning of the first reward location therefore did not affect their long-term memory for the first reward location.

Memory for the second reward location. There was an effect of drug that approached significance, $F(1,5)=5.48 p<.07$, and a significant effect of delay, $F(1,5)=18.05 p<.01$. The Drug $\times$ Delay interaction was also significant, $F(1,5)=9.67 p<.05$. Planned comparisons revealed that birds made significantly more errors during the 24-hr retrieval test when 180 min separated the two learning episodes and birds received AP5 prior to learning the second reward location, than when 15 min separated the two learning episodes and they received AP5 prior to learning the second reward location, paired $t(4)=2.74, p<.05$. Likewise, birds made more errors during retrieval when $180 \mathrm{~min}$ separated the two learning episodes and birds received AP5 prior to learning, than when 180 min separated the two learning episodes and they received saline prior to learning, paired $t(4)=3.80 p<.05$ (Figure 6).

These results demonstrate that AP5 infusion disrupts long-term memory for locations depending on the length of the interval between learning the locations. If a 15-min interval separates learning two reward locations, then AP5 administration prior to learning the second reward location does not disrupt long-term memory formation. If a 180-min interval separates learning two reward locations, then AP5 administration prior to learning the second reward location disrupts long-term memory formation. Furthermore, these results demonstrate that context familiarity affects the likelihood that memory formation will be disrupted by AP5 administration. We rearranged the feeders for each condition, thus providing birds with a novel context for each condition. This may explain why we found no impairment following AP5 administration in the 15-min delay condition.

\section{Cannula Placements}

Figure 7 summarizes the positions of the cannulas for each bird, based on the location of tissue damage. For 1 bird, both cannulas were positioned caudal and lateral to the HF. This bird was excluded from the statistical analyses.

\section{Discussion}

We have shown that NMDA-R activity in the HF of blackcapped chickadees is necessary for the formation of long-term spatial memories. Prior research has shown that NMDA-Rs are needed for correct homing in homing pigeons (Riters \& Bingman, 1994). Our data are the first to show that NMDA-Rs are necessary for flexible spatial memory such as that used by birds in food caching and retrieval. We were able to determine, in the same individual birds, which of the different phases of memory formation are sensitive to NMDA-R activity because our treatments were temporary and reversible. As Experiment 1 demonstrates, NMDA-R inactivation specifically affects processes occurring during memory acquisition, whereas retrieval processes, as well as short-term retention, are not affected by NMDA-R inactivation. Likewise, postacquisition processes of memory consolidation do not seem to require NMDA-R activity in the HF, as we found no disruptive effects of inactivating NMDA receptors immediately following a learning episode in Experiment 2. We showed in Experiment 3 that the interval length between successive learning episodes determines whether NMDA-R activity is necessary for encoding multiple serially presented reward locations. NMDA-R activity was required to encode a second reward location after a long interval between presentations of two reward locations.

Our aim in these experiments was to prevent NMDA-Rdependent synaptic plasticity and observe its effects on memory. To prevent synaptic plasticity, we infused antagonists to the 

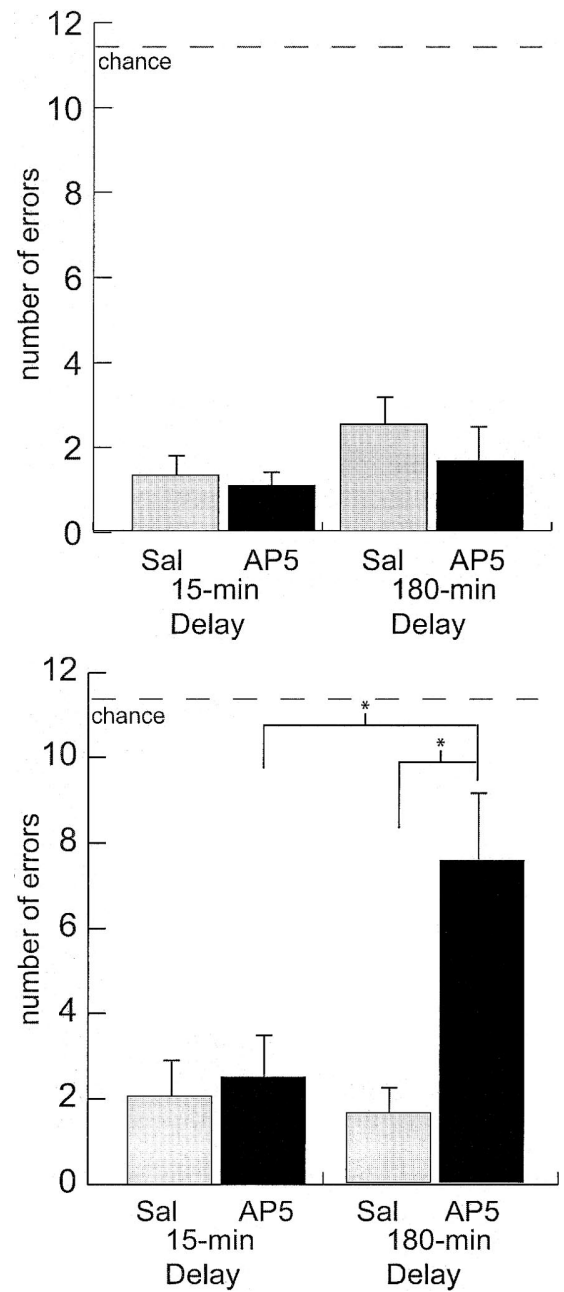

Figure 6. Results of Experiment 3: Birds' memory for the first (top) and second (bottom) reward locations was probed during the 24-hr retrieval test. Birds learned the second reward location either 15 or 180 min after learning the first reward location. Birds checked significantly more feeders to find the second rewarded location when receiving D-2 amino 5-phosphonopentanoic acid (AP5) after a long delay between learning episodes than after a short delay between learning episodes. Likewise, birds checked significantly more feeders to find the second rewarded location when they received AP5 after a long delay between learning episodes than when they received saline. $* p<.05$.

NMDA-R directly into the HF. We observed no motivational or motor-related deficits resulting from our treatment, leading us to conclude that the treatment specifically affects processes involved in memory. One issue this study does not address, however, is whether our treatment had any effect on markers of synaptic plasticity, such as long-term potentiation (LTP). In fact, LTP can be induced in a portion of the avian HF independent of NMDA-R activation (Margrie, Rostas, \& Sah, 1998; Wieraszko \& Ball, 1993). Subregions within the mammalian hippocampus vary in terms of their dependence on NMDA-R activation to induce LTP (Bliss \& Collingridge, 1993; Malenka \& Nicoll, 1993). Whether regional differences in the properties of LTP exist in the avian HF is not known.
We implanted cannulas in the dorsocaudal portion of the HF. This area has been recently hypothesized, on the basis of electrophysiological and connectivity data, to be equivalent to the dentate gyrus subregion of the mammalian hippocampus (Siegel, Nitz, \& Bingman, 2002; Szekely, 1999; Szekely \& Krebs, 1996). It was recently shown that NMDA-R activation in the different subregions of the mammalian hippocampus make different contributions to long-term memory formation. NMDA-R activation in the CA3 subregion is necessary for spatial reorganization and formation of new place fields, whereas the dentate gyrus/CA1 subregions are important for creating memories that persist over time (Kentros et al., 1998; Lee \& Kesner, 2002). We find that inactivating NMDA-Rs in this dorsocaudal region prevents acquisition of long-term memories, a result similar to what is observed in rat CA1. This further supports the notion of functional homology between the avian $\mathrm{HF}$ and mammalian hippocampus.

In mammals, the effects of hippocampal NMDA-R inactivation on the formation of long-term spatial memory depend on the learning situation and prior experience of the animal being tested.

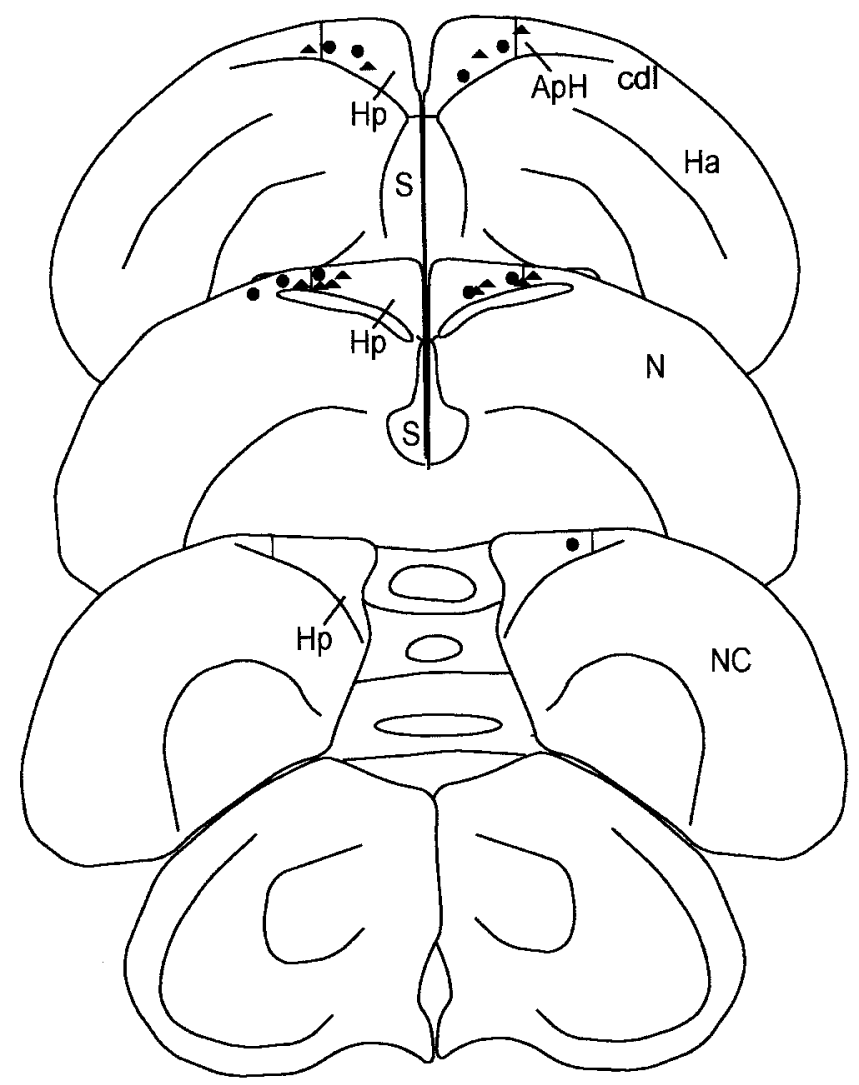

Figure 7. Position of cannulas. The positions of the symbols in brain slices correspond with the position of cannula tips for each subject. Circles indicate cannula locations for subjects used in Experiment 1, and triangles indicate cannula positions for subjects used in Experiment 2. The position of cannulas was mainly confined to the hippocampal formation, which consists of the area parahippocampalus $(\mathrm{ApH})$ and hippocampus proper (Hp). Sections correspond roughly with Karten and Hodos (1967) templates A 6.75, A 5.75, and A 4.00, rostral to caudal. cdl = caudo-dorsolateral striatum; $\mathrm{Ha}=$ hyperstriatum accessorium; $\mathrm{N}=$ neostriatum; $\mathrm{NC}=$ neostriatum caudale; $\mathrm{S}=$ septum. 
In rats, prior experience in a water maze makes hippocampal NMDA-R activity unnecessary for long-term memory formation (Bannerman et al., 1995; Moser \& Moser, 2000; Saucier \& Cain, 1995). One instance in which pretraining in the water maze does not protect the rat's memory from NMDA-R inactivation is when the task requires the rat to remember a hidden platform whose location is changed daily (Steele \& Morris, 1999). This task differs from other water maze tasks in that the rat must form a new memory of the hidden platform location each day, while it also learns to avoid the location it used on the previous day. An important aspect of this task is that the rat must reuse the same set of visual cues to identify the new location. The rat may form a new memory of the hidden platform in this situation by modifying its previously stored long-term memory of the spatial layout and incorporating the new location into its existing long-term memory. Such an operation may require NMDA-R-dependent synaptic plasticity.

Similar to the study of Steele and Morris (1999), we found that memory acquisition in a familiar environment depends on NMDA-R activity. In Experiment 1, we kept the configuration of feeders fixed across all conditions, and only the location of the rewarded feeder changed each day. Birds with NMDA-R blockade showed a deficit in forming new memories in this situation, which required birds to redefine the same set of cues to encode the new rewarded location each day. Likewise, in Experiment 3, we found that encoding a second reward location required NMDA-R activation if a long delay separated the first and second learning episodes. If a short delay separated learning the first and second rewarded location, then NMDA-R activation was not necessary for long-term memory formation. The lack of a memory deficit for the first reward location was presumably a result of rearranging the feeders each day. These trial-unique cues have been shown to prevent the memory deficits caused by NMDA-R antagonists (Bannerman et al., 1995; Moser \& Moser, 2000; Saucier \& Cain, 1995).

We assume that the long delay in Experiment 3 allowed the memory for the first location to be established into long-term memory, whereas the short delay did not. These results are consistent with the notion that NMDA-R activity is necessary for creation of new memories that incorporate elements of a network of previously consolidated long-term memories. Whether this process involves an interaction of hippocampal and other telencephalic structures, as is likely the case in mammals (Bontempi, Laurent-Demir, Destrade, \& Jaffard, 1999; Squire, 1992; Teng \& Squire, 1999; Zola-Morgan \& Squire, 1990), or is due to a remodeling of synaptic connections within the avian HF is not known.

The pharmacological effects of AP5 infusion span the acquisition period as well as a time period following memory acquisition. Both acquisition and postacquisition processes could be disrupted by our treatment, and both could contribute to long-term memory formation. In Experiment 2, we addressed this issue by antagonizing NMDA receptors immediately following a learning episode. We found no disruptive effect of our treatment on the formation of long-term memory. This is in contrast to findings from rats (Shimizu et al., 2000; Wittenberg, Sullivan, \& Tsien, 2002). We cannot claim, however, complete NMDA inactivation throughout the HF for the entire period occurring after the learning episode, as is the case with knockout mice lacking the NR1 subunit of NMDA-R in CA1. Therefore, NMDA-R activity may still have occurred, and such activation may have allowed for the persistence of long-term memory.

The neural mechanisms underlying black-capped chickadees' memory for spatial locations are likely to be the same mechanisms they use to remember the locations of their hidden caches. Because a chickadee's memory for cache locations is a long-term memory, these memories are likely to depend on features that can initiate plastic changes at synapses, such as activation of NMDA-Rs. It is possible, then, that alteration in the distribution or function of NMDA-Rs could be responsible for some aspect of the memory specialization in food-storing birds. In mice, overexpression of the NMDA-R subunit $2 \mathrm{~B}$ in the hippocampus is associated with a facilitation of LTP induction and superior performance in memory tasks, suggesting that the density of NMDA-Rs is positively related to the ability to induce plastic changes at synapses (Tang et al., 1999). Current data indicate that, if anything, there are fewer NMDA-Rs expressed in the HF of food-storing species compared with non-food-storing species (Stewart et al., 1999). It may be that reduced NMDA-R expression in some way facilitates the type of memory food-storing birds use to retrieve their hidden caches. Alternatively, reduced NMDA-R expression in food-storing birds may be a consequence of their expanded HF and may not by itself represent an adaptation in memory.

One proposed function of the mammalian $\mathrm{HF}$ is for integrating new information into long-term memory (Hasselmo \& McClelland, 1999; McClelland et al., 1995; Sutherland \& McNaughton, 2000). Our results suggest that the avian HF possesses a similar function and may rely on similar neural mechanisms, thereby extending the notion of functional homology between the mammalian and avian HF (Colombo \& Broadbent, 2000; Lee, Miyasato, \& Clayton, 1998). Furthermore, the mechanisms of long-term memory in food-storing birds are likely to underlie memory for cache locations in the wild. The results presented here provide a framework for examination of the relationship between neural adaptations and behavioral specializations in food-storing birds.

\section{References}

Balda, R. P., Kamil, A. C., Bednekoff, P. A., \& Hile, A. G. (1997). Species differences in spatial memory performance on a three-dimensional task. Ethology, 103, 47-55.

Bannerman, D., Good, M., Butcher, S., Ramsay, M., \& Morris, R. (1995, November 9). Distinct components of spatial learning revealed by prior training and NMDA receptor blockade. Nature, 378, 182-186.

Basil, J. A., Kamil, A. C., Balda, R. P., \& Fite, K. V. (1996). Differences in hippocampal volume among food storing corvids. Brain, Behavior and Evolution, 47, 156-164.

Bednekoff, P. A., Balda, R. P., Kamil, A. C., \& Hile, A. G. (1997). Long term spatial memory in four seed caching corvid species. Animal Behaviour, 53, 335-341.

Biegler, R., McGregor, A., Krebs, J. R., \& Healy, S. D. (2001). A larger hippocampus is associated with longer-lasting spatial memory. Proceedings of the National Academy of Sciences, USA, 98, 6941-6944.

Bingman, V. P., \& Yates, G. (1992). Hippocampal lesions impair navigational learning in experienced homing pigeons. Behavioral Neuroscience, 106, 229-232.

Bliss, T. V. P., \& Collingridge, G. L. (1993, January 7). A synaptic model of memory: Long-term potentiation in the hippocampus. Nature, 361, 31-39.

Bolhuis, J., \& Macphail, E. (2001). A critique of the neuroecology of learning and memory. Trends in Cognitive Sciences, 5, 426-433. 
Bolhuis, J. J., \& Reid, I. C. (1992). Effects of intraventricular infusions of the $N$-methyl-D-aspartate (NMDA) receptor antagonist AP5 on spatial memory of rats in a radial arm maze. Behavioural Brain Research, 47, 151-157.

Bontempi, B., Laurent-Demir, C., Destrade, C., \& Jaffard, R. (1999, August 12). Time-dependent reorganization of brain circuitry underlying long-term memory storage. Nature, 400, 671-675.

Caramanos, Z., \& Shapiro, M. (1994). Spatial memory and $N$-methyl-Daspartate receptor antagonists APV and MK-801: Memory impairments depend on familiarity with the environment, drug dose, and training duration. Behavioral Neuroscience, 108, 30-43.

Clayton, N. S., \& Krebs, J. R. (1994). One-trial associative memory: Comparison of food-storing and non-storing species of birds. Animal Learning and Behavior, 22, 366-372.

Colombo, M., \& Broadbent, N. (2000). Is the avian hippocampus a functional homologue of the mammalian hippocampus? Neuroscience and Biobehavioral Reviews, 24, 465-484.

Colombo, M., Swain, N., Harper, D., \& Alsop, B. (1997). The effects of hippocampal and area parahippocampalis lesions in pigeons: I. Delayed matching to sample. Quarterly Journal of Experimental Psychology: Comparative and Physiological Psychology, 50(B), 149-171.

Hampton, R. R., Sherry, D. F., Shettleworth, S. J., Khurgel, M., \& Ivy, G. (1995). Hippocampal volume and food-storing behavior are related in parids. Brain, Behavior and Evolution, 45, 54-61.

Hampton, R., \& Shettleworth, S. (1996a). Hippocampal lesions impair memory for location, but not color, in passerine birds. Behavioral Neuroscience, 110, 831-835.

Hampton, R. R., \& Shettleworth, S. J. (1996b). Hippocampus and memory in a food-storing and in a nonstoring bird species. Behavioral Neuroscience, 110, 946-964.

Hasselmo, M. E., \& McClelland, J. L. (1999). Neural models of memory. Current Opinion in Neurobiology, 9, 184-188.

Healy, S. D., \& Krebs, J. R. (1992). Food storing and the hippocampus in corvids: Amount and volume are correlated. Proceedings: Biological Sciences, 248, 241-245.

Healy, S. D., \& Krebs, J. R. (1996). Food storing and the hippocampus in Paridae. Brain, Behavior and Evolution, 47, 195-199.

Kamil, A. C., Balda, R. P., \& Olson, D. J. (1994). Performance of four seed-caching corvid species in the radial-arm maze analog. Journal of Comparative Psychology, 108, 385-393.

Karten, H. J., \& Hodos, W. (1967). A stereotaxic atlas of the brain of the pigeon (Columba livia). Baltimore: Johns Hopkins Press.

Kentros, C., Hargreaves, E., Hawkins, R., Kandel, E., Shapiro, M., \& Muller, R. (1998, June 26). Abolition of long-term stability of new hippocampal place cell maps by NMDA receptor blockade. Science, 280, 2121-2126.

Krebs, J. R., Clayton, N. S., Healy, S. D., Cristosl, D. A., Patel, S. N., \& Jolliffe, A. R. (1996). The ecology of the avian brain: Food-storing memory and the hippocampus. Ibis, 138, 34-46.

Lee, D. W., Miyasato, L. E., \& Clayton, N. S. (1998). Neurobiological bases of spatial learning in the natural environment: Neurogenesis and growth in the avian and mammalian hippocampus. NeuroReport, 9, $15-27$.

Lee, I., \& Kesner, R. P. (2002). Differential contribution of NMDA receptors in hippocampal subregions to spatial working memory. Nature Neuroscience, 5, 162-168.

Macphail, E. M., \& Bolhuis, J. J. (2001). The evolution of intelligence: Adaptive specializations versus general process. Biological Reviews of the Cambridge Philosophical Society, 76, 341-364.

Malenka, R. C., \& Nicoll, R. A. (1993). NMDA-receptor-dependent synaptic plasticity: Multiple forms and mechanisms. Trends in Neuroscience, 16, 521-532.

Margrie, T. W., Rostas, J. A., \& Sah, P. (1998). Long-term potentiation of synaptic transmission in the avian hippocampus. Journal of Neuroscience, 18, 1207-1216.

McLelland, J. L., McNaughton, B. L., \& O'Reilly, R. C. (1995). Why there are complementary learning systems in the hippocampus and neocortex: Insights from the successes and failures of connectionist models of learning and memory. Psychological Review, 102, 419-457.

Morris, R., Anderson, E., Lynch, G., \& Baudry, M. (1986, February 27) Selective impairment of learning and blockade of long-term potentiation by an $N$-methyl-D-aspartate receptor antagonist, AP5. Nature, 319, $774-776$.

Moser, M. B., \& Moser, E. I. (2000). Pretraining and the function of hippocampal long-term potentiation. Neuron, 26, 559-561.

Olson, D. J., Kamil, A. C., Balda, R. P., \& Nims, P. J. (1995). Performance of four seed-caching corvid species in operant tests of nonspatial and spatial memory. Journal of Comparative Psychology, 109, 173-181.

Pravosudov, V. V., \& Clayton, N. S. (2002). A test of the adaptive specialization hypothesis: Population differences in caching, memory, and the hippocampus in black-capped chickadees (Poecile atricapilla). Behavioral Neuroscience, 116, 515-522.

Riters, L., \& Bingman, V. (1994). The NMDA-receptor antagonist MK801 impairs navigational learning in homing pigeons. Behavioral and Neural Biology, 62, 50-59.

Saucier, D., \& Cain, D. (1995, November 9). Spatial learning without NMDA receptor-dependent long-term potentiation. Nature, 378, 186189.

Shapiro, M. L., \& Caramanos, Z. (1990). NMDA antagonist MK-801 impairs acquisition but not performance of spatial working and reference memory. Psychobiology, 18, 231-243.

Sherry, D. F., \& Vaccarino, A. L. (1989). Hippocampus and memory for food caches in black-capped chickadees. Behavioral Neuroscience, 103, $308-318$.

Sherry, D. F., Vaccarino, A. L., Buckenham, K., \& Herz, R. S. (1989). The hippocampal complex of food-storing birds. Brain, Behavior and Evolution, 34, 308-317.

Shiflett, M. W., Gould-Beierle, K. L., Smulders, T. V., \& DeVoogd, T. J. (2002). Septum volume and food-storing behavior are related in parids. Journal of Neurobiology, 51, 215-222.

Shiflett M. W., Smulders T. V., Benedict L., \& DeVoogd, T. J. (2003). Reversible inactivation of the hippocampal formation in food-storing black-capped chickadees (Poecile atricapullus). Hippocampus, 13, $437-$ 444.

Shimizu, E., Tang, Y.-P., Rampon, C., \& Tsien, J. Z. (2000, November 10). NMDA receptor-dependent synaptic reinforcement as a crucial process for memory consolidation. Science, 290, 1170-1174.

Siegel, J. J., Nitz, D., \& Bingman, V. P. (2002). Electrophysiological profile of avian hippocampal unit activity: A basis for regional subdivisions. Journal of Comparative Neurology, 445, 256-268.

Smulders, T. V., \& DeVoogd, T. J. (2000) The avian hippocampal formation and memory for hoarded food: Spatial learning out in the real world. In J. Bolhuis (Ed.), Brain, perception, memory. Advances in cognitive neuroscience (pp. 127-148). Oxford, England: Oxford University Press.

Smulders, T. V., Sasson, A. D., \& DeVoogd, T. J. (1995). Seasonal variation in hippocampal volume in a food-storing bird, the blackcapped chickadee. Journal of Neurobiology, 27, 15-25.

Smulders, T. V., Shiflett, M. W., Sperling, A. J., \& DeVoogd, T. J. (2000). Seasonal changes in neuron numbers in the hippocampal formation of a food-hoarding bird: The black-capped chickadee. Journal of Neurobiology, 44, 414-422.

Squire, L. (1992). Memory and the hippocampus: A synthesis from findings with rats, monkeys, and humans. Psychological Review, 99, 195231

Steele, R. J., \& Morris, R. G. M. (1999). Delay-dependent impairment of 
a matching-to-place task with chronic and intrahippocampal infusion of the NMDA-antagonist D-AP5. Hippocampus, 9, 118-136.

Stewart, M. G., Cristol, D., Philips, R., Steele, R. J., Stamatakis, A., Harrison, E., \& Clayton, N. (1999). A quantitative autoradiographic comparison of binding to glutamate receptor sub-types in hippocampus and forebrain regions of a food-storing and a non-food-storing bird. Behavioural Brain Research, 98, 89-94.

Sutherland, G. R., \& McNaughton, B. (2000). Memory trace reactivation in hippocampal and neocortical neuronal ensembles. Current Opinion in Neurobiology, 10, 180-186.

Szekely, A. D. (1999). The avian hippocampal formation: Subdivisions and connectivity. Behavioural Brain Research, 98, 219-225.

Szekely, A. D., \& Krebs, J. R. (1996). Efferent connectivity of the hippocampal formation of the zebra finch (Taeniopygia guttata): An anterograde pathway tracing study using Phaseolus vulgaris leucoagglutinin. Journal of Comparative Neurology, 368, 198-214.

Tang, Y. P., Shimizu, E., Dube, G., Rampon, C., Kerchner, G., Zhuo, M. G. L., \& Tsien, J. (1999, September 2). Genetic enhancement of learning and memory in mice. Nature, 401, 63-69.
Teng, E., \& Squire, L. R. (1999, August 12). Memory for places learned long ago is intact after hippocampal damage. Nature, 400, 675-677.

Tsien, J., Huerta, P., \& Tonegawa, S. (1996). The essential role of hippocampal CA1 NMDA receptor-dependent synaptic plasticity in spatial memory. Cell, 87, 1327-1338.

Wieraszko, A., \& Ball, G. F. (1993). Long-term potentiation in the avian hippocampus does not require activation of the $N$-methyl-D-aspartate (NMDA) receptor. Synapse, 13, 173-178.

Wittenberg, G., Sullivan, M., \& Tsien, J. (2002). Synaptic reentry reinforcement based network model for long-term memory consolidation. Hippocampus, 12, 637-647.

Zola-Morgan, S., \& Squire, L. R. (1990, October 12). The primate hippocampal formation: Evidence for a time-limited role in memory storage. Science, 250, 288-290.

Received March 19, 2003

Revision received July 23, 2003

Accepted July 25, 2003

\section{Members of Underrepresented Groups: Reviewers for Journal Manuscripts Wanted}

If you are interested in reviewing manuscripts for APA journals, the APA Publications and Communications Board would like to invite your participation. Manuscript reviewers are vital to the publications process. As a reviewer, you would gain valuable experience in publishing. The $\mathrm{P} \& \mathrm{C}$ Board is particularly interested in encouraging members of underrepresented groups to participate more in this process.

If you are interested in reviewing manuscripts, please write to Demarie Jackson at the address below. Please note the following important points:

- To be selected as a reviewer, you must have published articles in peer-reviewed journals. The experience of publishing provides a reviewer with the basis for preparing a thorough, objective review.

- To be selected, it is critical to be a regular reader of the five to six empirical journals that are most central to the area or journal for which you would like to review. Current knowledge of recently published research provides a reviewer with the knowledge base to evaluate a new submission within the context of existing research.

- To select the appropriate reviewers for each manuscript, the editor needs detailed information. Please include with your letter your vita. In your letter, please identify which APA journal(s) you are interested in, and describe your area of expertise. Be as specific as possible. For example, "social psychology" is not sufficient-you would need to specify "social cognition" or "attitude change" as well.

- Reviewing a manuscript takes time (1-4 hours per manuscript reviewed). If you are selected to review a manuscript, be prepared to invest the necessary time to evaluate the manuscript thoroughly.

Write to Demarie Jackson, Journals Office, American Psychological Association, 750 First Street, NE, Washington, DC 20002-4242. 